\title{
La terapia para el virus de la inmunodeficiencia humana parece costo-efectiva en países de bajos recursos
}

Human inmuno defficiency virus treatment seams cost-effective in resource-poor settings

Goldie J y col. N Engl J Med 2006;355:1141-1153

\section{Objetivo}

Evaluar la costo-efectividad* de la terapia anti retroviral (TAR) en adultos de Costa de Marfil infectados con el virus de la inmunodeficiencia humana (VIH).

\section{Métodos}

Comparación de los efectos clínicos y económicos en el largo plazo en una cohorte simulada* con un promedio de edad de 33 años, de recuento de CD4 331/mm3 y de ARN VIH 5,3 copias log/mL. Las intervenciones evaluadas fueron cuatro: 1) no tratamiento; 2) sólo profilaxis con trimetoprima-sulfametoxazol (TMS); 3) sólo TAR; 4) TMS más TAR.

\section{Resultados}

Comparándolas con el uso exclusivo de TMS, la ganancia de expectativa de vida osciló entre 10,7 meses con TAR y TMS iniciada según criterios clínicos, y 45,9 meses con TAR y TMS iniciada por valores de CD4 y criterios clínicos. El costo incremental por año de vida ganado fue 240 u\$s para TMS sola; 620 para TAR y TMS iniciada por criterios clínicos; y 1.180 para TAR y TMS iniciadas por valores de CD4 y criterios clínicos (cada una comparada con la estrategia siguiente menos costosa). Ver tabla 1. Ninguna de las estrategias que utilizó TAR exclusivamente fue tan costo-efectiva como las que además utilizaron TMS. La expectativa de vida se incrementaba $30 \%$ usando una TAR de segunda generación luego de la falla de una de primera.
Tabla 1: beneficios clínicos y costo-efectividad de las estrategias más eficientes.

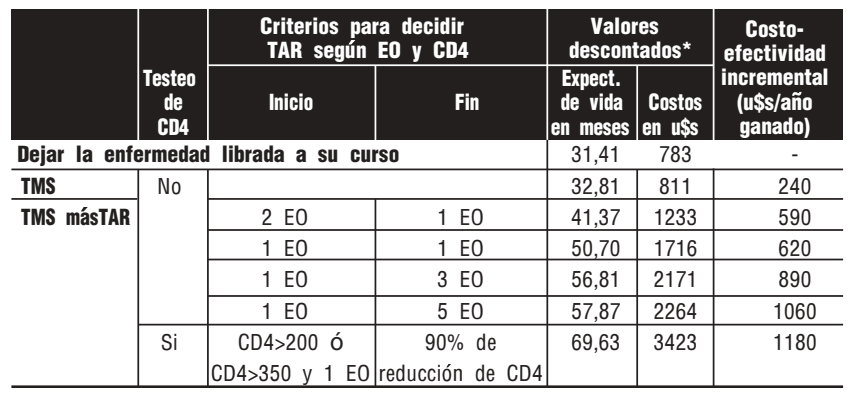

EO: enfermedad oportunista (infección micótica severa, isosporiasis, toxoplasmosis, micobacteriosis no tuberculosas y otras enfermedades severas). TMS: profilaxis con trimetoprima-sulfametoxazol. TAR: terapia anti-retroviral.

\section{Conclusiones}

La profilaxis con TMS y la TAR según criterios clínicos o combinándolas con los valores de CD4 para decidir el inicio, es una inversión atractiva en países con recursos limitados.

Palabras Clave: virus de la inmunodeficiencia humana, costo-efectividad. Key words: human inmuno-deficiency virus, cost-effectiveness. Fuente de financiamiento: Agencias estatales de EE.UU y Francia.

\section{Comentario}

Las evaluaciones económicas son cada vez más utilizadas para decidir cuáles tratamientos eficaces o efectivos vale la pena financiar'. Las agencias regulatorias (FDA en EE.UU, EMEA en la Unión Europea, ANMAT en Argentina) incorporan cada vez más esta "cuarta valla" para la asignación de recursos sanitarios ${ }^{2}$, siendo las otras tres la calidad, la seguridad y la eficacia de las intervenciones. La implementación de estrategias de expansión del acceso a los TAR en países de bajos o medianos recursos promovida por la Organización Mundial de la Salud (OMS) fue criticada por su presunta menor eficacia, adherencia y costo-efectividad en estos escenarios $^{3}$. Sin embargo, la realidad ha demostrado lo contrario ${ }^{4,5}$, resultando comprensible la costo-efectividad de un tratamiento combinado de TAR y profilaxis de infecciones oportunistas como el que comentamos, implementado sobre la base de los estándares de seguimiento actuales que incluyen el recuento de linfocitos $T$ CD4+.

El mismo énfasis que se ha puesto destinar fondos al acceso a
TAR y a la reducción de su costo, debe ponerse en su implementación en los escenarios de mayor costo-efectividad y en el desarrollo de infraestructura y recursos humanos idóneos, para multiplicar y sostener los logros frente a una epidemia en avance ${ }^{6}$.

Conclusión de los comentadores

Si no se dispone de testeo de CD4, la provisión de TMS y TAR según los criterios de inicio temprano y discontinuación tardía serían costo-efectivas en países de bajos y medianos recursos; y la estrategia más efectiva (testeo de CD4 y criterios clínicos) tamutilización de recursos. En este sentido, el horizonte de la costoefectividad nos ayudará a alejarnos del riesgo de los dobles estándares $^{7}$. bién lo sería. Debemos contribuir a establecer pautas propias de

Ver glosario*

Federico Augustovski [ Servicio de Medicina Familiar y Comunitaria. Hospital Italiano de Buenos Aires ]

Waldo H. Belloso [ Sección Infectología, Hospital Italiano de Buenos Aires ]

Augustovski F, Belloso W. La terapia para el VIH en países de bajos recursos parece costo-efectiva. Evid. Actual. Pract. Ambul. 10(1):15 Ene-Feb. 2007. Comentado de: Goldie S, Yazdanpanah Y, Losina E et al. Cost-Effectiveness of HIV Treatment in Resource-Poor Settings - The Case of Côte d'Ivoire. N Engl J Med. 2006;355(11):1141-53. PMID: 16971720

\section{Referencias}

1. Claxton K, Sculpher M, Drummond M. A rational framework for decision making by the National Institute For Clinical Excellence (NICE). Lancet. 2002;360(9334):711-5

2. Taylor RS, Drummond MF, Salkeld G, Sullivan SD. Inclusion of cost effectiveness in licensing requirements of new drugs: the fourth hurdle. BMJ. 2004;329(7472):972-5.

3. Scaling up antiretroviral therapy in resource-limited settings: treatment guidelines for a public health approach -2003 revision. Geneva: World Health Organization 2003 (Acceso: 22 Dic 2006 a: http://www.who.int/3by5/publications/documents/arv guidelines/en/.)

4. Mills EJ, Nachega JB, Buchan I, Orbinski J, Attaran A, Singh S, Rachlis B, Wu P, Cooper C, Thabane L, Wilson K, Guyatt GH, Bangsberg DR. Adherence to antiretroviral therapy in sub-Saharan Africa and North America: a meta-analysis. JAMA 2006 Aug 9, 296(6):679-90. Review.

5. Weidle PJ, Wamai N, Solberg P, Liechty C, Sendagala S, Were W, Mermin J, Buchacz K, Behumbilze P, Ransom RL, Bunnell R. Adherence to antiretroviral therapy in a home-based AIDS care programme in rural Uganda. Lancet 2006 Nov 4; 368(9547): 1578-94.

6. Steinbrook R. Message from Toronto - Deliver AIDS treatment and prevention. N Engl J Med 2006 Sept 14; 355(11): 1081-4.

7. Moatti JP, Spire B, Kazatchkine M. Drug resistance and adherence to HIV/AIDS antiretroviral treatment: against a double standard between the north and the south. AIDS 2004 Jun; 18 (Suppl3): S55-61. 